\title{
Proceeding
}

Supplementary Issue: Spring Conferences of Sports Science. Costa Blanca Sports Science Events, 14-15 June 2019. Alicante, Spain.

\section{Player Performance Model, comparison between youth professional (U-21) and professional first team football players: Different external load or not?}

\author{
RICCARDO IZZO ${ }^{1}$, CIRO HOSSEINI VARDE'I ${ }^{1}$, GAETANO RAIOLA², FILIPPO SANTINELLI ${ }^{1}$ \\ 1 University Carlo Bo of Urbino, Italy \\ 2University of Salerno, Italy
}

\begin{abstract}
During last years the use of new technologies, become crucial to define physical performance, tactics, and technique in football. The physical performance during matches is detected, using video-analysis or GPS system. The aim of this study was to compare external load performance from matches between young professional players (U-21) and professional players from European leagues. Data from U-21 was collected using K-Sport $10 \mathrm{~Hz}$ GPS (K-Sport Universal, Italy) using as a sample of three Italian youth teams. Data from professional players are taken from video-analysis gathered from the literature. Were analysed 10 games for each youth teams from Italian Primavera Championship 2016/2017. For every game was used one $10 \mathrm{~Hz}$ GPS (K-Sport Universal, Italy) for each player, except goalkeeper and were recorded only data from players that perform all the game. Keywords: Player Performance Model; Match analysis; External load; Professional and Youth comparison.
\end{abstract}

Cite this article as:

Izzo, R., Varde'i, C.H., Raiola, G., \& Santinelli, F. (2019). Player Performance Model, comparison between youth professional (U-21) and professional first team football players: Different external load or not? . Journal of Human Sport and Exercise, 14(4proc), S991-S996. doi:https://doi.org/10.14198//hse.2019.14.Proc4.61

Corresponding author. University Carlo Bo of Urbino, Italy.

E-mail: riccardo.izzo@uniurb.it

Supplementary Issue: Spring Conferences of Sports Science. Costa Blanca Sports Science Events, 14-15 June 2019. Alicante, Spain.

JOURNAL OF HUMAN SPORT \& EXERCISE ISSN 1988-5202

(c) Faculty of Education. University of Alicante

doi:10.14198/jhse.2019.14.Proc4.61 


\section{INTRODUCTION}

In modern soccer, fitness performance control and regulation is regarded as a relevant methodological procedure to optimize training adaptations in order to maximize match performance results [1]. Physiological fitness increase is the result of the interplay of external and internal loads imposed on players during training sessions [2]. The recent exponential advancement of match analysis systems such as multi-camera and Global Position System (GPS) Technology has enabled the evaluation of player's external load during specific training and match in elite and sub-elite level [3]. Monitoring trainings and matches using video tracking and GPS system have provided to create a database, in order to better examine team and individual performance [4]. The aim of this study is to detect physical performance from 3 youth professional team using $10 \mathrm{~Hz}$ GPS and compare the obtained data with professional players data gathered from the literature. We know from literature [5] that footballers traveled on average a distance of $10 \mathrm{Km}$ per game, with changes of intensity every 3 to 5 seconds characterized by moments of high energy engagement (30\% of total effort, about 200 high-intensity actions per game) and low engagement moments (70\% of total effort). Football is therefore considered an aerobic/anaerobic alternate sport, where maximum sprints, directional changes, elevations, contrasts are performed, with more or less short recovery phases. The player performance model (PPM) is multidisciplinary and dynamic [6]. Then PPM is a set of complex interactions, formed, as mentioned, by various components at the same time, and it must be dynamic and adaptable to the match situations, in fact, it varies for instance from the category or from country to country, according to the game styles and the characteristics of the athletes involved in the matches [7]. Mohr et al [8] demonstrated that the players gait in the field for most of the time at low speed, making about $10 \mathrm{Km}$ per game and energy expenditure of 61 $\mathrm{KJ} / \mathrm{KG}, 42 \%$ of which is given by the high-intensity actions. During matches, players perform sprints every 90 seconds, each with an average of 2-4 seconds duration, they covered the $0.5 \%-3 \%$ of total playing time. Normally they are in $96 \%$ of cases shorter than $30 \mathrm{Mt}$ and in the $50 \%$ shorter than $10 \mathrm{Mt}$ [9]. Accelerations and decelerations are another determinant aspect, respectively for accelerations are calculated from 2.5 to $4 \mathrm{~ms}^{2}$ and decelerations -2.5 to $-4 \mathrm{~ms}^{2}$, players produce an average of 100 variations for each match. Are also evaluated the intense accelerations $\left(\mathrm{IA}>4 \mathrm{~ms}^{2}\right)$ and intense decelerations $\left(\mathrm{ID}<-4 \mathrm{~ms}^{2}\right)$ that are around 10 per game [10]. The studies we saw have been made on professional footballers, with this study, could be possible to define a PPM for youth professional footballers, in order to compare and evaluate individual performance and to help teams and coaches to select players, from an objective point of view, at least in physical performance. External training load is usually the sum of distances and time performed in arbitrary speed thresholds. Recently a metabolic power (MP) approach was proposed to provide an instantaneous idea of soccer-specific activities [11]. This method considers acceleration and speed to detect individual distances and time spent by players at one arbitrary chosen estimated power threshold. MP approach may provide more detailed tracking of players activities. The metabolic approach assumes that the energy produced by a player during actual match play is a direct result of the product of the running cost from acceleration and the corresponding instantaneous speed [12].

\section{MEANS AND METHOD}

The aim of this study was to compare external load performance from matches between the young professional player (U-21) and professional players from Italian first league championship. Data from U-21 was collected using K-Sport $10 \mathrm{~Hz}$ GPS (K-Sport Universal, Italy) using as sample three Italian youth teams (Team A, Team B, Team C). Data from the professional player are taken from video-analysis gathered from literature [13]. Were analyzed 10 games for each youth teams from Italian Primavera Championship 2016/2017. For every game were used one $10 \mathrm{~Hz}$ GPS (K-Sport Universal, Italy) for every player except goalkeepers, but were recorded only data from players that played the full match. In total, we recorded data 
from 43 different players ( 13 from Team A, 14 from Team B and 16 from Team C). The database was of 220 detections, with an average detection for the match (A.D.M) of 7,3 for the game (Table 1).

Table 1. Total detections gathered team by team and relative A.D.M

\begin{tabular}{lcc}
\hline \multicolumn{1}{c}{ Team } & Detections & A.D.M \\
\hline Team A & 70 & 7.0 \\
Team B & 73 & 7.3 \\
Team C & 77 & 7.7 \\
Total & 220 & 7.3 \\
\hline
\end{tabular}

Data average for the study group were age $17 \pm 1$, height $1,82 \mathrm{~cm} \pm 4$ and weight $75 \pm 5$. Period of analysis was going from September 2017 to November 2017. The following parameters were taken into consideration:

- $\quad$ Total Distance (meters, D);

- $\quad$ Distance per minutes (meters/minutes, Drel);

- $\quad$ Distance at High Intensity Speed $>16 \mathrm{Km} / \mathrm{h}$ (meters, D_SHI);

- $\quad$ Distance at High Intensity Metabolic Power $>20$ W/kg (meters, D_MPHI);

- $\quad$ Distance at Very High Acceleration $>3 \mathrm{~m} / \mathrm{s}^{2}$ (meters, D_AccHI);

- $\quad$ Distance at Very High Deceleration $<3 \mathrm{~m} / \mathrm{s}^{2}$ (meters, D_DecHI);

- $\quad$ Average Metabolic Power (watt $\mathrm{kg}^{-1}, \mathrm{AMP}$ ).

Data were processed with proprietary software (K-Fitness, K-Sport Universal, Montelabbate, PU, Italy) and then analysed with commercially available spreadsheets (Excel, Microsoft, USA).

\section{DATA ANALYSIS AND DISCUSSION}

Data were presented as mean \pm standard deviation, maximum and minimum value for the total amount of data and divided by team (Tables 2,3,4).

Table 2. Data from External Load Performance of Team A

\begin{tabular}{lccccccc}
\hline & \multicolumn{7}{c}{ Team A } \\
\hline & D & Drel & D_SHI & D_MPHI & D_AccHI & D_DecHI & AMP \\
\hline Average & 10217 & 109 & 1670 & 2854 & 201 & 188 & 10.2 \\
SD & 677 & 8 & 418 & 437 & 39 & 38 & 0.8 \\
Max & 11937 & 132 & 2721 & 3810 & 274 & 294 & 12.4 \\
Min & 9015 & 93 & 989 & 1974 & 112 & 129 & 8.4 \\
\hline
\end{tabular}

Table 3. Data from External Load Performance of Team B

\begin{tabular}{lccccccc}
\hline & \multicolumn{7}{c}{ Team B } \\
\hline Average & 9617 & Drel & D_SHI & D_MPHI & D_AccHI & D_DecHI & AMP \\
SD & 701 & 1411 & 2543 & 183 & 167 & 9.5 \\
Max & 11212 & 7 & 337 & 421 & 30 & 28 & 0.7 \\
Min & 8282 & 86 & 2481 & 3710 & 261 & 243 & 11.0 \\
\hline
\end{tabular}


Table 4. Data from External Load Performance of Team C

\begin{tabular}{lccccccc}
\hline & \multicolumn{7}{c}{ Team C } \\
\hline Average & 9706 & Drel & D_SHI & D_MPHI & D_AccHI & D_DecHI & AMP \\
SD & 624 & 7 & 1393 & 2509 & 173 & 153 & 9.4 \\
Max & 11447 & 120 & 2463 & 447 & 30 & 35 & 0.6 \\
Min & 8723 & 87 & 763 & 1810 & 121 & 90 & 8.1 \\
\hline
\end{tabular}

Team A in comparisons with other teams recorded the higher value in every parameter analysed, in the other hands Team C, shows the lowest standard deviation, this indicates that the sample was more homogeneous. Data from professional (Table 5) are gathered from literature and were detected with video tracking analysis from European Leagues. Table 6 shows total average comparison from analysed teams and European leagues, professional recorded higher value in every parameter detected except for D_MPHI that are higher in Team A. Table 6 shows caparison between Pro and analysed U-21 teams, professional players recorded higher value in every parameter except in relation to the Team $A$ in the parameters D_MPHI, D_AccHI and D_DecHl.

Table 5. Data from External Load of Professional

\begin{tabular}{lccccccc}
\hline & \multicolumn{7}{c}{ Italian Professional First League (Castagna et al. 2016) } \\
\hline & D & Drel & D_SHI & D_MPHI & D_AccHI & D_DecHI & AMP \\
\hline Average & 10673 & 116 & 1778 & 2759 & 210 & 215 & 10.7 \\
SD & 347 & 4 & 208 & 241 & 48 & 56 & 0.5 \\
\hline
\end{tabular}

Table 6. Data Comparison between Professional and U-21 detected Teams

\begin{tabular}{lccccccc}
\hline & \multicolumn{7}{c}{ Total Comparison } \\
\hline & D & Drel & D_SHI & D_MPHI & D_AccHI & D_DecHI & AMP \\
\hline Pro & 10673 & 116 & 1778 & 2759 & 209 & 215 & 10.7 \\
Team A & 10217 & 109 & 1670 & 2854 & 201 & 188 & 10.2 \\
Team B & 9617 & 101 & 1411 & 2543 & 183 & 167 & 9.5 \\
Team C & 9706 & 101 & 1393 & 2509 & 173 & 153 & 9.4 \\
\hline
\end{tabular}

Total comparison between average data from U-21 teams and professional players are shown in Table 7. Professional players:

- $\quad$ On D shows value $8 \%$ higher, with a lower S.D;

- $\quad$ On Drel shows a value $11 \%$ higher, with a lower S.D;

- $\quad$ On D_SHI shows a value $11 \%$ higher, with lower S.D;

- $\quad$ On D_MPHI shows a value $16 \%$ higher, with lower S.D;

- $\quad$ On D_AccHI shows a value 5\% higher, with higher S.D;

- $\quad$ On D_DecHI shows a value $12 \%$ higher, with higher S.D;

- $\quad$ On AMP shows a value $10 \%$ higher, with lower S.D. 
Table 7. Data Comparison between Professional and U-21

\begin{tabular}{cccccccc}
\hline \multicolumn{7}{c}{ Average Comparison } \\
\hline & D & Drel & D_SHI & D_MPHI & D_AccHI & D_DecHI & AMP \\
\hline Pro & $10672 \pm 347$ & $116 \pm 4$ & $1778 \pm 208$ & $2758 \pm 241$ & $210 \pm 48$ & $215 \pm 56$ & $10.7 \pm 0.5$ \\
U-21 & $9822 \pm 743$ & $103 \pm 8$ & $1488 \pm 391$ & $2627 \pm 462$ & $185 \pm 35$ & $168 \pm 37$ & $9.6 \pm 0.8$ \\
$\%$ Dif. & $8 \%$ & $11 \%$ & $16 \%$ & $5 \%$ & $12 \%$ & $22 \%$ & $10 \%$ \\
\hline
\end{tabular}

\section{CONCLUSION}

The aim of this study was to investigate the differences between physical performance data from matches between professional U-21 and professional players. The comparison was made using $10 \mathrm{~Hz}$ GPS system for analysing three youth teams; data from professional are obtained from the literature. As predictable in total average professional players recorded higher value in every parameter detected. Parameters that showed higher percentage difference are D_SHI (20\%) and D_DecHI (19\%); these parameters are correlated with high intensity events. This demonstrates that professional players had a better physical fitness in comparisons with U-21. This can be also correlated with a better tactical and technical preparation that helps professional to understand the moments of matches in order to use energy in an appropriate way. This difference between professionals and U-21 players can also be traced back to the reason for a non-excellent technique and tactic that leads to a longer and more frequently interruptions during matches that create a consequently shorter effective time of play and a lower average in high intensity parameters. In order to establish this can be useful to produce future studies, taking in consideration even differences between first and second half or even by divided matches in quarters. Platts (2012) with a study in the football youth academy, determinate that $99 \%$ of players from football youth academy don't obtain a professional contract at the end of their football academy career [14]. An evolution of this study can be useful in order to better understand the real value of young player, and to help coaches to identify talent (at least in physical values), as we know, nonlinear sprint differentiate professional players from young soccer players [15], analysing other parameters, will be possible to refine talent research. These studies could be perfected, with a full season monitoring on the U-21 championship and a higher frequency device, in order to detect, an amount of data, less affected by errors and fortuity. This situation would allow us to detect athletic differences during the various phases of the season [16], considering above all that such studies do not exist in the scientific literature. In order to determine exactly performance models for these categories, further studies are needed. It will be interesting even to compare athletes, dividing positions $[17,18]$ and minutes played, to determine the real performance parameters for each role.

\section{REFERENCES}

Sarmento H., Marcelino R., Anguera M.T., Campani J., Matos N., LeitAo J.C. 2014. "Match analysis in football: a systematic review." Journal of Sports Sciences. 2014;32:1831-1843. https://doi.org/10.1080/02640414.2014.898852

Impellizzeri F.M., Rampinini E., Marcora S.M. 2005. "Physiological assessment of aerobic training in soccer." J Sports Sci. 2005;23:583 - 592. https://doi.org/10.1080/02640410400021278

Buchheit M., Allen A., Poon T.K., Modonutti M., Gregson W., Di Salvo V. 2014. "Integrating different tracking systems in football: multiple camera semi-automatic system, local position measurement and GPS technologies." Journal of Sports Sciences. 2014;32:1844-1857. https://doi.org/10.1080/02640414.2014.942687

D'Isanto, T., D'Elia, F., Raiola, G., \& Altavilla, G. (2019). Assessment of sport performance: theoretical aspects and practical indications. Sport Mont, 17(1), 79-82. https://doi.org/10.26773/smj.190214 
Castagna C, Varley M, Póvoas SCA, D'Ottavio S. 2016. "The Evaluation of the Match External Load in Soccer: Methods Comparison." Int J Sports Physiol Perform. 2017 Apr;12(4):490-495. https://doi.org/10.1123/ijspp.2016-0160

Izzo, R., De Vanna, A., Hosseini Varde'i, C. 2018. "Data Comparison between Elite and Amateur Soccer Players by $20 \mathrm{~Hz}$ GPS Data Collection." Journal of Sports Science 6 (2018) 31-35. https://doi.org/10.17265/2332-7839/2018.01.004

Izzo, R., and Sopranzetti, S. 2016. "Speed, Acceleration, Deceleration and Metabolic Power in the Work to Roles for a Workout more Targeted in Elite Football." International Journal of Physical Education, Sport and Health 2 (2): 2394-1685.

Mohr, M., Krustrup, P., and Bangsbo, J. 2003. "Match Performance of High-Standard Soccer Players with Special Reference to Development of Fatigue." Journal of Sports Sciences 21 (7): 519-28. https://doi.org/10.1080/0264041031000071182

Dwyer, D.B., and Gabbett, T. 2011. "global positioning system data analysis: velocity ranges and a new definition of sprinting for field sport athletes." Journal of Strength and Conditioning Research, $0(0) / 1-$ 7. https://doi.org/10.1519/jsc.0b013e3182276555

Stølen T, Chamari K, Castagna C, Wisløff U. Physiology of Soccer: An Update. Sports Med. 2005;35:501-536. https://doi.org/10.2165/00007256-200535060-00004

Osgnach, C., Poser, S., Bernardini, R., Rinaldo, R., and Di Prampero, P. E. 2010. "Energy Cost and Metabolic Power in Elite Soccer: A New Match Analysis Approach." Medicine \& Science in Sports \& Exer-cise 42 (1): 170-8. https://doi.org/10.1249/mss.0b013e3181ae5cfd

Hoppe, M.W., Baumgart, C., Slomka, M., Polglaze, T., and Freiwald, J. 2017. "Variability of Metabolic Power Data in Elite Soccer Players During Pre-Season Matches." J Hum Kinet. 2017 Aug 1;58:233245. https://doi.org/10.1515/hukin-2017-0083

Castagna C, Varley M, Póvoas SCA, D'Ottavio S. 2016. "The Evaluation of the Match External Load in Soccer: Methods Comparison." Int J Sports Physiol Perform. 2017 Apr;12(4):490-495. https://doi.org/10.1123/ijspp.2016-0160

Platts, C. 2012. "Education and welfare in professional football academies and centres of excellence: A sociological study." (Unpublished doctoral dissertation). University of Chester, United Kingdom.

Cardoso de Araújo M., Baumgart C., Freiwald J., Hoppe M.W. 2017 "Nonlinear sprint performance differentiates professional from young soccer players." J Sports Med Phys Fitness. https://doi.org/10.23736/S0022-4707.17.07116-X

Altavilla, G., Riela, L., Di Tore, A.P., Raiola, G. (2017) The physical effort required from professional football players in different playing positions. Journal of Physical Education and Sport, 17 (3), 20072012.

Altavilla, G., Mazzeo, F., D'Elia, F., Raiola, G. (2018) Physical commitment and specific work for each role in an elite soccer team, Journal of Physical Education and Sport, 18 (2), 570-574.

Raiola, G., D'isanto, T. (2016) Assessment of periodization training in soccer. Journal of Human Sport and Exercise, 11 267-278. https://doi.org/10.14198/jhse.2016.11.Proc1.19

\section{(9) $(\mathbb{Q} \Theta \Theta$}

This work is licensed under a Attribution-NonCommercial-NoDerivatives 4.0 International (CC BY-NC-ND 4.0). 